\title{
Influence of green polyhydroxylic compounds on copper nano thin film deposition
}

\author{
P. BalaRamesh ${ }^{1,}$, P. Venkatesh ${ }^{2}$, and S. Jayalakshmi ${ }^{2}$ \\ ${ }^{1}$ Associate Professor, RMK Engineering College, Chennai, Tamilnadu, India. \\ ${ }^{2}$ Associate Professor, Pachaiyappa's College, Chennai, Tamilnadu, India. \\ ${ }^{2}$ Research Scolar, Pachaiyappa's College Chennai, Tamilnadu, India. \\ Corresponding Author*P. BalaRamesh, E-mail: balarameshp@gmail.com
}

\begin{abstract}
In this work, we utilized the regular polyhydroxylic complexing agents' saccharose and xylitol to develop an eco-friendly electroless deposition process for copper. The electroless bath used formaldehyde free glyoxylic acid as reducing agent and $\mathrm{KOH}$ as the $\mathrm{pH}$ adjustor, rather than $\mathrm{NaOH}$, to avoid the development of insoluble by-product. A small volume of the green Bronsted acid, methanesulphonic acid (MSA) was also used in the bath to improve solubility of the copper salts. The surface morphologies and structural property of copper deposits were characterized by SEM, AFM and XRD studies. Pyridine and 2,2-dipyridyl as primary stabilizers in saccharose and xylitol baths were found to influence the deposition rate and thickness of the copper deposits. In the saccharose bath, Pyridine performed as inhibitors and best deposition was obtained at pH of 12.75. 2,2-dipyridyl afforded smoother and shiner deposits than Pyridine. In xylitol bath, both the stabilizers were best deposition occurred at a $\mathrm{pH}$ of 13.25 and served as the accelerator and extended the life of the electroless bath.
\end{abstract}

Key words: biodegradable, pyridine, reducing agent, saccharose, xylitol.

\section{I.INTRODUCTION}

First report of electroless copper deposition from a solution of copper and formaldehyde by Narcus [1] and Chattway [2] in 1947, and the first commercial use of the technique by Cahil [3] and Zeblisky [4] et al. There has been widespread use of this technique in a variety of applications. Recent applications that employ electroless plating include through-hole plating (THP) in printed circuit boards (PCBs) and creating decorative articles with coating [5-8]. Polyhydroxylic compounds have therefore gained importance as chelants in electroless plating because they are easily bio-degradable [9-12] similarly, the more ecofriendly methanesulphonic acid (MSA) is being increasingly used in electroless copper plating instead of conventionally used fluoroboric acid. Additions of small amounts of MSA have been reported to produce uniform and high quality coatings [13-18]. In this work, we report the use of pyridine and 2,2-dipyridyl as primary stabilizers in electroless copper methanesulphonate, saccharose and xylitol baths. Use of these stabilizers results in high quality deposits as established using SEM, AFM, XRD testing.

\section{EXPERIMENTAL WORK}

The following chemicals were used for the study.

\section{CHEMICALS AND SOLUTIONS:}

1. Copper as methane sulphonate $-3 \mathrm{~g} / \mathrm{L}$ : synthesized in-house from copper carbonate

2. Saccharose $-20 \mathrm{~g} / \mathrm{L}$

3. Xylitol $-20 \mathrm{~g} / \mathrm{L}$

3. Glyoxylic acid $-10 \mathrm{~mL} / \mathrm{L}$

4. $\mathrm{KOH}$ - upto $\mathrm{pH} 13.25$

5. Temperature $-45^{\circ} \mathrm{C}$

6. Stabilizers - Pyridine and 2,2-dipyridyl - 1 ppm

An environmentally friendly bath for electroless deposition of copper was prepared using 
methanesulphonate, saccharose, xylitol, Glyoxylic acid, and potassium hydroxide (to vary the $\mathrm{pH}$ of the bath), with added stabilizers. The electroless $\mathrm{Cu}$ deposition was performed on a $\mathrm{Cu}$ sheet $(2.0 \times 2.0 \times 0.1 \mathrm{~cm})$ in a 100 $\mathrm{mL}$ beaker. Before deposition, the $\mathrm{Cu}$ substrate was rinsed with double distilled water after polishing with fine grid paper. A scoring process was used to clean the precleaned substrates using $\mathrm{KOH}$ solution. After rinsing with distilled water, surface etching process was performed using a solution of $\mathrm{KMnO}_{4}$ and $\mathrm{H}_{2} \mathrm{SO}_{4}$ to remove any oxidized layer on the surface. In order to improve the deposition rate and adhesive properties of the $\mathrm{Cu}$ nano thin film, the surface was sensitized using $\mathrm{SnCl}_{2}$ solution $\left(\mathrm{SnCl}_{2}\right.$ mixed with $\left.\mathrm{HCl}\right)$ and activated using an $\mathrm{HCl}$ solution of $\mathrm{PdCl}_{2}$.

\section{CALCULATION FOR RATE, THICKNESS OF COPPER DEPOSITS:}

Rate of the electroless copper deposit was calculated using the following equation

$$
\text { Rate of deposition }(\mu \mathrm{m} / \mathrm{h})=\text { Thickness / Deposition time }
$$

From the weight of the deposit, total plated area and density of the copper, the thickness was calculated as follows.

$$
\operatorname{Thickness}(\mu \mathrm{m})=\frac{W \times 10^{4} \times 60}{A \times d}
$$

The surface topography was evaluated using scanning electron microscope (SEM-Carlzeiss MA-150). Atomic force microscope (AFM) (NanoSurf Easy Scan2, Switzerland) was used to analyze the surface roughness of the nano copper deposits. X-ray diffraction, (X'Pert-Pro, P-analytical) was used to identify the structural properties of the nano copper deposits.

The Debye-Scherrer equation $[19,20]$ for calculating the particle size is given by

$$
D=K \lambda / \beta \cos \theta
$$

where, $\mathrm{K}$ is the Scherrer constant, $\lambda$ is the wavelength of light used for the diffraction, $\beta$ is the 'Full Width Half Maximum' of the sharp peaks and $\theta$ is the angle measured. The Scherrer constant (K) in the above formula accounts for the shape of the particle and is generally taken to have the value 0.89 .

\section{III.RESULTS AND DISCUSSION}

\section{PHYSICAL PROPERTIES:}

The deposition rates were determined using physical weight gain method and the thickness of the copper deposits were determined by simple gravimetric formula. $1 \mathrm{ppm}$ 2,2-dipyridyl was used as the bath stabilizer and acted as an enhancer in both saccharose and xylitol containing electroless copper methanesulphonate bath. Because of the rates of deposition were greater than plain baths, the complexation stability 2,2-dipyridyl bath may be less than in plain baths. The thickness of deposition increased on increasing plating time duration and thickness value gradually increased 2,2-dipyridyl bath rather than the plain baths.

Table 1. Surface morphologies on, saccharose and xyliotol plain baths containing methane sulphonate bath.

\begin{tabular}{|l|l|l|l|l|}
\hline Surface morphologies & $\begin{array}{l}\text { Saccharose } \\
\text { Plain bath }\end{array}$ & $\begin{array}{l}\text { Pyridine } \\
\text { Bath }\end{array}$ & Xylitol bath & $\begin{array}{l}\text { 2,2-dipyridyl } \\
\text { Bath }\end{array}$ \\
\hline Crystallite size $(\mathrm{nm})$ & 136 & 130 & 128 & 124 \\
\hline Deposition rate $(\mu \mathrm{m} / \mathrm{h})$ & 2.62 & 2.86 & 3.02 & 3.21 \\
\hline Roughness value $(\mathrm{nm})$ & 340 & 146 & 316 & 182 \\
\hline $\mathrm{E}_{\text {corr }}$ values & -436.4 & -489.66 & -441.77 & -498.68 \\
\hline Thickness $(\mu \mathrm{m})$ & 157.2 & 171.6 & 181.2 & 192.6 \\
\hline Double layer Capacitance $\left(\mathrm{C}_{\mathrm{d} 1}\right), \mathrm{C}_{2} \times 10^{-3}$ & 0.1286 & 0.1086 & 0.1421 & 0.0827 \\
\hline Charge transfer Resistance $\left(\mathrm{R}_{\mathrm{t}}\right)$ & 29.76 & 52.39 & 30.23 & 28.57 \\
\hline
\end{tabular}




\section{SURFACE MORPHOLOGY:}

The two dimensional structure of deposited copper was studied by SEM analysis. The surface morphology of copper deposits was studied by scanning electron microscopy (SEM) analysis at magnification of $\mathrm{x}$ 1000 and $\mathrm{x} 5000$ for the specimen used in plain bath and additive baths. Figure 1 show that regular and fine grained copper deposits were obtained when the additives were added to the saccharose bath. Addition of small volume of stabilizers not only stabilizes the bath and also changes the physical features such as colour, shape and crystallite size of the copper deposits.

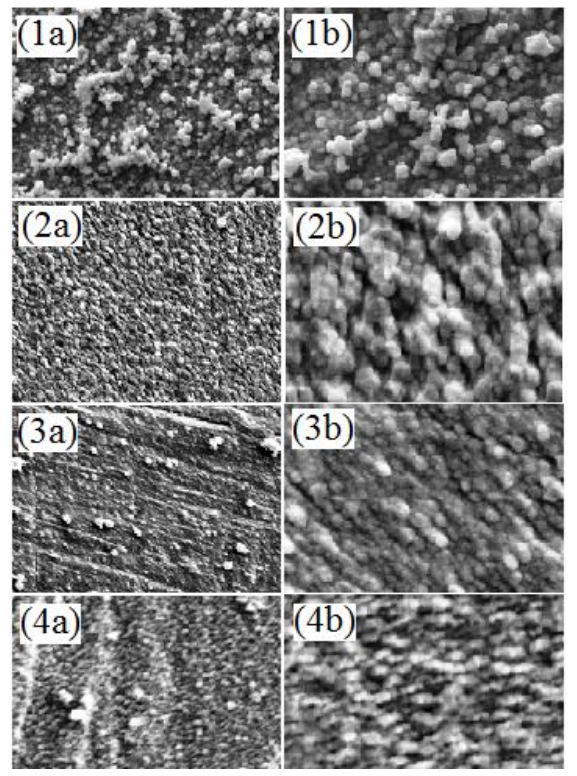

Fig.1. SEM images of copper deposits on methanesulphonate saccharose and xylitol plain baths with stabilizers

(1 ppm), (a) magnification 1000 and (b) magnification 5000, (1) saccharose plain bath (2) pyridine bath, (3) xylitol plain bath and (4) 2,2-dipyridyl bath.

AFM images of copper deposits on methanesulphonate baths with saccharose and xylitol and with and without stabilizer were studied. The (a) topography (b) 3-D image and (c) surface area of the deposits were observed.

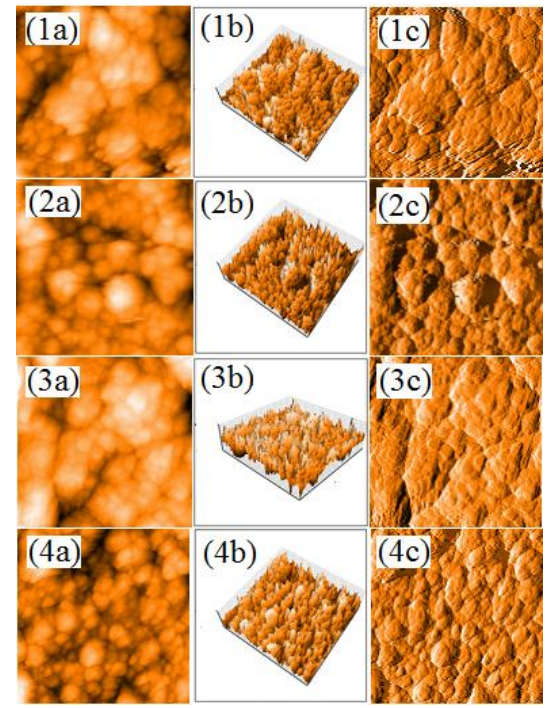

Fig.2. AFM images of copper deposits on methanesulphonate saccharose and xylitol plain bath (a) topography of copper deposits (b) 3-D image and (c) surface area.

The saccharose plain bath produced maximum roughness of $340 \mathrm{~nm}$. Figure 2 and table. 1 shows that the deposits were dark brown for saccharose baths without stabilizers. However, on addition of $1 \mathrm{ppm}$ of pyridine and 2,2-dipyridyl the deposits became semi bright. Xylitol plain bath produced bright copper deposits with a roughness value of $303 \mathrm{~nm}$. 


\section{ELECTROCHEMICAL PROPERTIES:}

\section{Electrochemical Impedance Spectroscopy (EIS):}

Interfacial charge transfer between the solid conductor and the electrolyte was investigated using electrochemical impedance spectroscopy. The values of charge transfer resistance and double layer capacitance were obtained for saccharose and xylitol containing electroless copper methanesulphonate baths.

Table 1 and figure 4 indicates the value of $\mathrm{C}_{\mathrm{dl}}=0.1286$ and $0.1421 . \mathrm{R}_{\mathrm{t}}=29.76$ and 30.23 are observed in plain baths. The corrosion inhibition efficiency was due to the presence of hetero atom, electron density at donor sites and availability of functional group.

\section{Cyclic Voltammetry (CV):}

The inhibiting and enhancing properties of stabilizers can be understood from the anodic peak current value, anodic peak potential value and peak appearance. Based on CV studies, the inhibiting properties of the stabilizer result in low anodic peak potential values. The low-energy oxidation process is enhanced by stabilizers. Figure 3 show that the appearances of the sharp peaks indicate that the rate of oxidation is high.

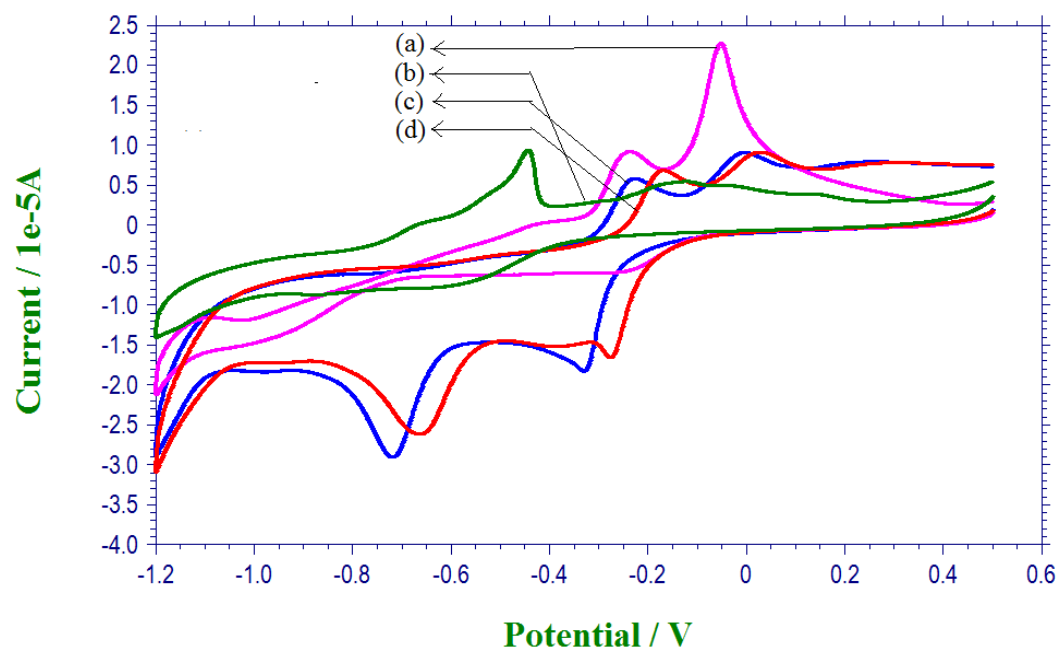

Fig.3 Cyclic voltammogram for electroless copper methanesulphonate xylitol bath at $p \mathrm{H} 13.25 ; 2,2$ '-bipyridine bath (a), Saccharose plain bath (b), xylitol plain bath (c), pyridine bath (d).

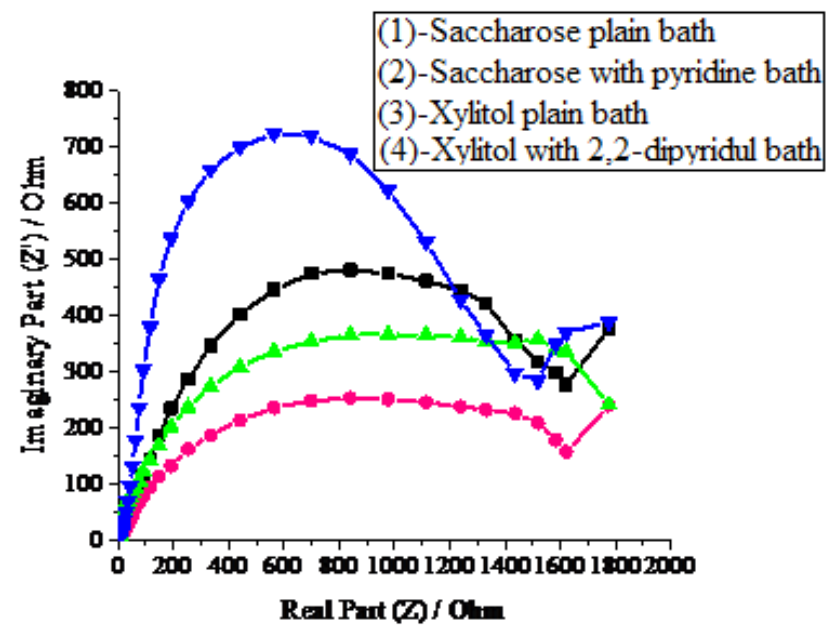

Fig .4 Nyquist diagram of electroless copper methanesulphonate saccharose plain bath with stabilizers (1 ppm) (1) pyridine bath (2) saccharose plain bath, (3) 2,2-dipyridyl and (4) xylitol plain bath. 


\section{Tafel Polarization (TP):}

Corrosion kinetics parameters such as $\mathrm{E}_{\text {corr }}$ and $\mathrm{I}_{\text {corr }}$ value were determined by the Tafel polarization technique. Deposition rates were determined using these above Tafel parameters values from figure 5 show that the inhibiting and accelerating effect of stabilizers confirmed the results observed using xylitol plain bath. Both physical and electrochemical results of the deposition rate showed similar effects. Thus, there is good agreement in the behavior of stabilizers in xylitol bath.

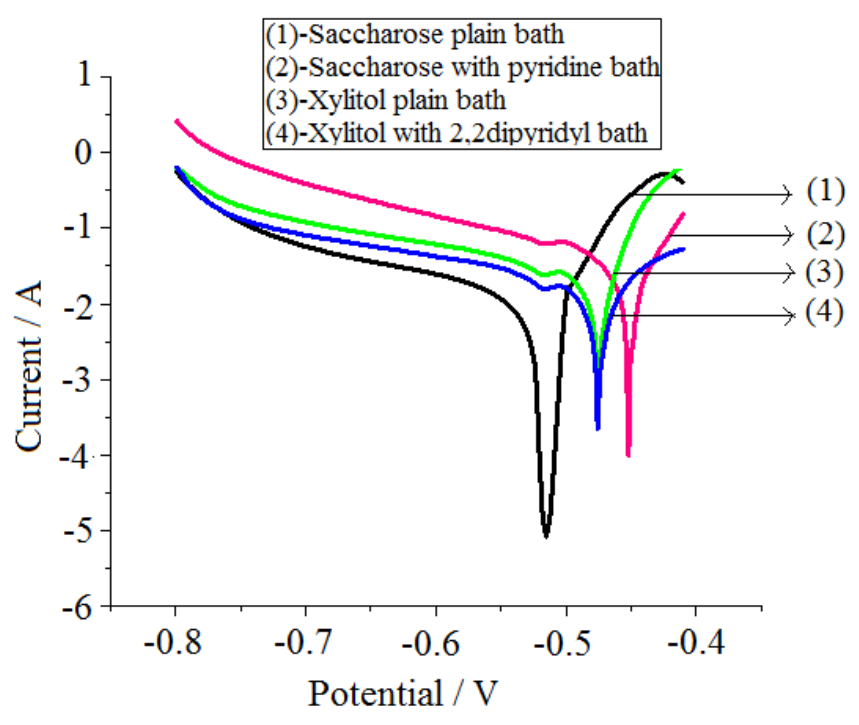

Fig. 5. Tafel polarization curve for electroless copper methanesulphonate saccharose plain bath with stabilizers (1 ppm) (1) pyridine bath (2) saccharose plain bath, (3) 2,2-dipyridyl and (4) xylitol plain bath.

\section{STRUCTURAL PROPERTIES:}

Three major reflection planes were observed for the copper deposits, viz., (111), (200) and (220). The crystallographic texture of $\mathrm{Cu}$ is face-centered-cubic (FCC) and 111 is the closed packed plane in FCC structures. Thin films grown at low ion concentrations tend to have a preferred orientation of the 111 plane which is of lowest surface energy. However, when we used biodegradable Bronsted- metanesulphonic acid (MSA) as bath liquid, figure 3 show that the preferred orientation at (200) plane.

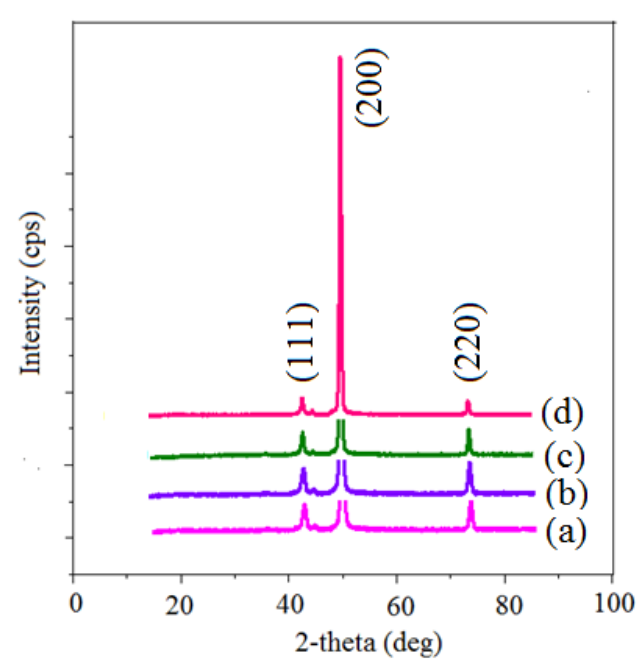

Fig.6. XRD pattern of copper deposits on methanesulphonate saccharose plain bath with stabilizers (1 ppm)

(a) pyridine bath (b) saccharose plain bath, (c) 2,2-dipyridyl and (d) xylitol plain bath. 
Crystallite sizes are proportional to the levels of inhibition of deposition. The crystallite sizes were found to be smaller in baths containing 2,2-dipyridyl than in saccharose and xylitol plain baths. The delocalized $\pi$-electrons in the phenyl ring and presence of hetero atom nitrogen appear to have an influence on the crystallite size.

\section{CONCLUSION}

Green polyhydroxylic compounds such as saccharose and xylitol containing copper methanesulponate with glyoxylic acid are stable baths in alkaline solution. Saccharose bath produces that attained maximum at $\mathrm{pH}$ 12.75 , and then slows at higher $\mathrm{pH}$. For xylitol containing baths, the electroless deposition starts at $\mathrm{pH}$ above 12.5 reaches maximum at $\mathrm{pH} 13.25$, and then slows at higher $\mathrm{pH}$ values. The copper deposits obtained in the plain saccharose bath were sand-like in morphology and plain xylitol bath had a grain-like structure. On the other hand in the presence of stabilizers, rock like, flower-like, honey comb structures were seen. Roughness value and crystallite size of the copper deposits were analyzed by AFM and XRD techniques. Physical and electrochemical experimental results prove saccharose and xylitol were to be a good metal complexing agent and pyridine and 2,2dipyridyl were good stabilizers in copper methanesulphonate bath. Moreover, smooth and shiny deposits were obtained on adding 2,2-dipyridyl to saccharose and xylitol baths.

\section{REFERENCES}

1. Narcus H., (1947), 'Practical copper reduction on nonconductors', Metal Finishing., Vol. 45, pp. 64-67.

2. Chattaway F.D., (1907), 'Copper mirrors', Proc. Roy. Soc., London, 80-A, pp. 88-92.

3. A CahillA.E.,(1957), 'American electrochemical society proceedings', Vol.44, pp. 130-135.

4. Zeblisky R.J., McCormack J.F., Williamson J.D., and Shneble F.W., (1963), U.S. Patent 3,095,309

5. Okinaka Y., Osaka T., Gerischer H., and Tobios C.W., (1994), 'Advances in Electrochem.Science and Engineering' (Eds). VCH, Weinheim, Vol. 3, pp. 55.

6. Sullivan E.J.O., in Alkica R.C., and Kolb D.M., (2002),(Eds) 'Advance in Electrochem.Science and Engineering', wiley.Weinheim, Vol-7, pp. 225-270

7. Norkus E., Prusinskas K., Vaskelis A., Jaciauskiene J., Stalnioniene I., and Macalady D.L., (2007), 'Application of saccharose as copper(II) ligand for electroless copper plating solutions', Carbohydrate Research, Vol. 342, pp. 71-78.

8. Schlesinger M., and Paunovic M., (2000), 'Modern electroplating'. $4^{\text {th }}$ edition, New York, John Wiley. Vol. 14, pp. 868.

9. Schlesinger M., (Editor), and Paunovic M., (Editor)., (2010), 'Modern Electroplating,' $5^{\text {th }}$ Edition, New York, John Wiley, pp. 736.

10. Hanna F., Hamid Z.A., and Aal A.A., (2003), 'Controlling factors affecting the stability and rate of electroless copper plating', Materials Letters, Vol. 58, pp. 104-109.

11. Balci S., Bittner A.M., Hahn K., Scheu C., Knez M., Kadri A., Wege C., Jeske H., and Kern K., (2006), 'Copper nanowires within the central channel of tobacco mosaic virus particles', Electrochimica Acta, Vol. 51, pp. 6251-6257.

12. Cho Sang Jin., Nguyen Trieu., and Boo Jin Hyo., (2011), 'Polyimide surface modification by using microwave plasma for adhesion enhancement of copper electroless plating', Journal of nanoscience and nanotechnology., Vol.11, pp. 5328-5333.

13. Guo R.H., Jiang S.X., Yuen C.W.M., Ng M.C.F., Lan J.J.W., Yeung Y.L., and Lin S.J., (2013), 'Effects of deposition parameters of electroless copper plating on polyester fabric', Fibers and Polymers., Vol. 14, pp. 752-758.

14. Hung A., and Ohno I., (1985.a), 'Effect of pH on hypophosphite reduced electroless copper', J. Plat. Surf. Fin., Vol. 77, pp. 5457.

15. Kshatriya R.B., Machhi J.K., and Nazeruddin G.M, (2014), 'Synthesis of flavanones using methanesulphonic acid as a green catalyst and comparision under different conditions', Oriental journal of chemistry, Vol. 30, pp. 857-862.

16. Jagannathan R., and Krishnan M., (1993), 'Electroless plating of copper at a low $p \mathrm{H}$ level', IBM. Journal of Research and Development, Vol. 37, pp. 117.

17. Leleti R.R., Hu B., Prashad M., and Repic O., (2007) 'Highly selective methanesulphonic acid-catalyzed 1,3-isomerization of allylic alcohols', Tetrahedron Letters, Vol. 48, pp. 8505- 8507.

18. Balaramesh P., Venkatesh P., Rekha S., and Hemamalini M., (2014.d), 'Bath parameters affecting electroless copper depositionA review', International journal of innovative research and studies, Vol. 3, pp. 167-181.

19. Debye P., and Scherrer P., (1917), 'x-ray Interference produced by irregularly oriented particles (III) x-rays,' Phys. Ziet., Vol. 18, pp. 291- 301.

20. Cullity B.D., (1978), 'Element of X-ray diffraction', Addison-Wesley, London. 